THURSDAY, OCTOBER 30, I9r 3.

\section{RADIATION THEORIES.}

Vorlesungen über die Theorie der Wärmestrahlung. By Dr. Max Planck. Zweite Auflage. Pp. xii + 206. (Leipzig: J. A. Barth, 19r3.) Price 7 marks.

THE first edition of this book, which appeared in 1906, was reviewed in NATURE (October II, 1906, Supplement iii.). The many and varied contributions to our knowledge of radiation phenomena that have been published in the ensuing seven years have made it necessary for Dr. Planck to rewrite and modify the book to a considerable extent, so that it now contains many novel features. As before, the object of the book is to apply the statistical methods previously used in the kinetic theory of gases to the phenomena of radiation, and full use is made of Boltzmann's views on the interpretation of entropy in connection with the theory of probability. But the present treatment is largely based on the remarkable assumption which the author designates as the "quantum-hypothesis."

The property thus assumed for the elementary electrical oscillators under consideration may perhaps best be explained by comparing them to the cisterns, of which many have been invented and which are so arranged that when the water in them reaches a certain level they overturn and empty themselves, then returning to their original position to be refilled. In other words, absorption takes place continuously, while emission occurs intermittently when the energy of the oscillator attains one or other of certain discrete values. This "quantum hypothesis," as the author points out, is analogous to the electron theory, which assigns a definite magnitude to the electron or "elementary quantum" of electricity. It accounts for Nernst's observed phenomena, and, further, it is in accordance with the view that every different radiation corresponds to a certain definite temperature, and it is already beginning to form an important element in present-day physical researches.

It need scarcely be pointed out that the quantum hypothesis entails irreversibility and thus overcomes a difficulty of the kinetic theory of gases, namely, that even statistical methods apparently fail to account for irreversible phenomena when applied to a system the elements of which are subject to the equations of reversible dynamics, unless some further assumption is made ("Assumption A" of the late Mr. Burbury). It will thus be seen that the present method does not pretend to afford a so-called "dynamical proof" of the phenomena of radiation, and in the preface Dr. Planck distinctly expresses the view that a new principle cannot in general be represented by a model working according to old laws. It will also be evident that brief indications of the new method, such as those contained in this notice, cannot be regarded as adequate descriptions of the real substance of Dr. Planck's investigations.

It was natural that a theory fraught with such far-reaching consequences should attract considerable attention at the recent meeting of the British Association, and the occasion was the more suitable as the presidency of Sir Oliver Lodge had attracted to the meeting a number of physicists all keenly interested in radiation theories. It would be undesirable to refer in greater length to these discussions, as they will be dealt with elsewhere. A popular account of modern radiation theories, including special reference to Dr. Plancks quantum hypothesis, was given by Dr. Max Born, of Gottingen, in Die Naturwissenschaften 2x, for May 28, p. 499.

It does not appear to the present reviewer that the quantum hypothesis is necessarily irreconcilable with dynamical principles. If we take the equations of motion of a dynamical system and write down the expressions for the second differential coefficients of the squares and products of its velocities, we obtain formulæ which may be said to determine the energy accelerations of the system in the same way that the ordinary equations of motion determine the accelerations of the masses. If we assume conditions of statistical equilibrium we find a definite amount of energy associated with a definite system, and we further find that certain conditions must hold in order that energy equilibrium may be possible. Such a method establishes a kind of principle of duality between the properties of matter and the properties of energy, and is distinctly favourable to an atomic theory of energy. But the attempt to reduce everything to dynamics would of course land us in the old difficulty over the irreversibility.

G. H. B.

\section{CHEMICAL TEXT-BOOKS.}

(I) Osmotic Pressure. By Prof. A. Findlay. Pp. $\mathrm{vi}+84$. (London: Longmans, Green \& Co., 1913.) Price 2s. $6 d$. net.

(2) The Organometallic Compounds of Zinc and Magnesium. By Dr. Henry Wren. Pp. viii + roo. (London: Gurney and Jackson, 1913.) Price $\mathrm{i} s .6 d$. net.

(3) The Chemistry of Dyeing. By Dr. J. K. Wood. Pp. vii +8 o. (London: Gurney and Jackson, 1913.) Price $1 s .6 d$. net. 